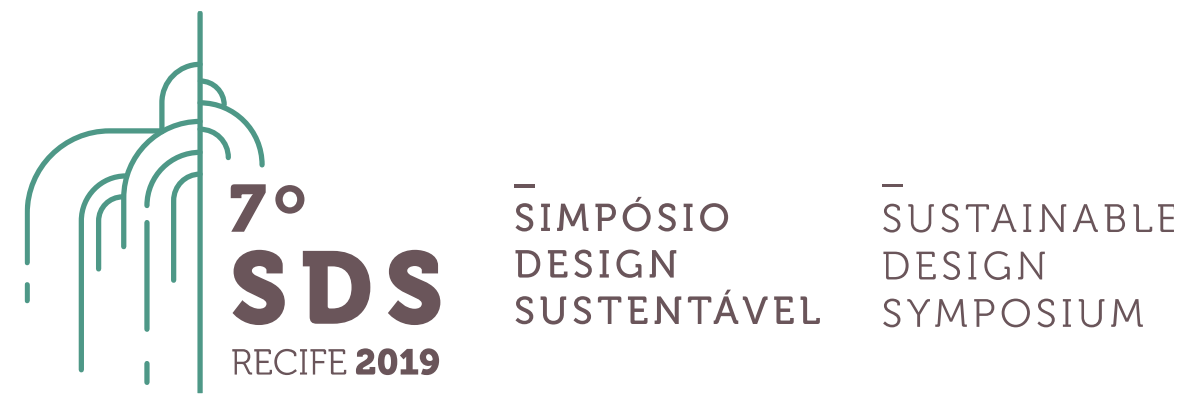

\title{
LIBRÁRIO: \\ DESIGN, TECNOLOGIA SOCIAL, INCLUSÃO E SUSTENTABILIDADE - ESTUDOS PARA CRIAÇÃO DE UM NOVO JOGO PEDAGÓGICO
}

\author{
Flávia Neves de Oliveira ${ }^{1}$, Rita de Castro Engler ${ }^{2}$, Nadja Maria Mourão ${ }^{3}$ \\ ${ }^{1}$ Universidade do Estado de Minas Gerais, Escola de Design-eudisseflavia@hotmail.com \\ ${ }^{2}$ Universidade do Estado de Minas Gerais, Escola de Design - rita.engler@gmail.com \\ ${ }^{3}$ Universidade do Estado de Minas Gerais, Escola de Design - nadjamourao@gmail.com
}

\begin{abstract}
Resumo. O Librário é um jogo desenvolvido como ferramenta facilitadora para tornar o ambiente de ensino inclusivo para os surdos. Esse jogo é constituído de um baralho de pares de cartas, contendo os sinais de Libras e as palavras em português. O objetivo dessa pesquisa é investigar os conteúdos da temática em Sustentabilidade, Meio Ambiente e Ciências Ambientais e dos sinais em libras, para o desenvolvimento do Librário Ambiental por meio dos recursos em design e da inclusão social dos surdos. Além da revisão temática, foi utilizado o método de experimentação. O Librário é uma ferramenta facilitadora da aprendizagem da Libras pelos ouvinte, promovendo a inclusão.
\end{abstract}

Palavras-chave: Design; Tecnologia Social; Libras; Meio Ambiente; Jogo Librário.

\section{Introdução}

O Librário é um jogo desenvolvido como ferramenta facilitadora para tornar o ambiente de ensino inclusivo para os surdos. Reconhecido como tecnologia social e certificado pela Fundação Banco do Brasil, o Librário se populariza em aplicações nas escolas, eventos, atividades em centros culturais e nas redes sociais. Esse jogo é constituído de um baralho de pares de cartas, contendo os sinais de Libras e as palavras em português. A prática do jogo facilita o aprendizado de sinais para ouvintes e viabiliza a comunicação entre surdos e ouvintes.

Trata-se de uma ferramenta pedagógica e imagética desenvolvida através de uma abordagem sistêmica, integral e inovadora do design e da arte, com perspectiva de alcançar a toda rede de ensino no território nacional. Foi desenvolvido no âmbito acadêmico extensivo que se firma pelo 
caráter científico, criativo e artístico, fator de cooperação entre universidade e sociedade inclusiva (CASTRO et al., 2016).

A metodologia dessa tecnologia social inclui a execução de oficinas em escolas, universidades e instituições para crianças e adultos, surdos e ouvintes, principalmente em cursos de formação de multiplicadores. Além do jogo de baralho, há também a versão digital. Trata-se de um aplicativo do jogo para download gratuito em celulares e computadores, com vídeos de sinais, que facilitam o processo de aprendizado da Libras de forma divertida e, consequentemente, promove a inclusão comunicacional dos surdos.

Por se tratar de um material de baixo custo e fácil reprodução, a proposta metodológica do Librário é acessível a qualquer pessoa ou instituição. Entre os objetivos do jogo, busca-se: possibilitar aos ouvintes o acesso a uma parte do vocabulário da Libras de forma dinâmica através; incentivar o reconhecimento da relação coerente entre palavra, imagem e sinal dentro do campo da arte; contextualizar as experiências da cultura e comunicação da comunidade surda, com recursos de imagens e contribuir para a integração entre surdos e ouvintes efetivamente (CASTRO, MOURÃO, 2018).

No momento, o Librário possui duas modalidades: uma com palavras do cotidiano e outra com palavras do campo semântico da arte. Com recursos de fundação científica de fomento, foram disponibilizadas as versões virtuais e gratuitas desses jogos em aplicativo para Android, iPhone/iPad, Windows e Mac.

Apresentam-se na figura 1, as imagens das versões digital e física do jogo Librário, que até o momento, oferecem duas modalidades: O Librário Geral e o Librário das Artes.

Figura 1: Librário Geral e das Artes, em formato digital e físico.

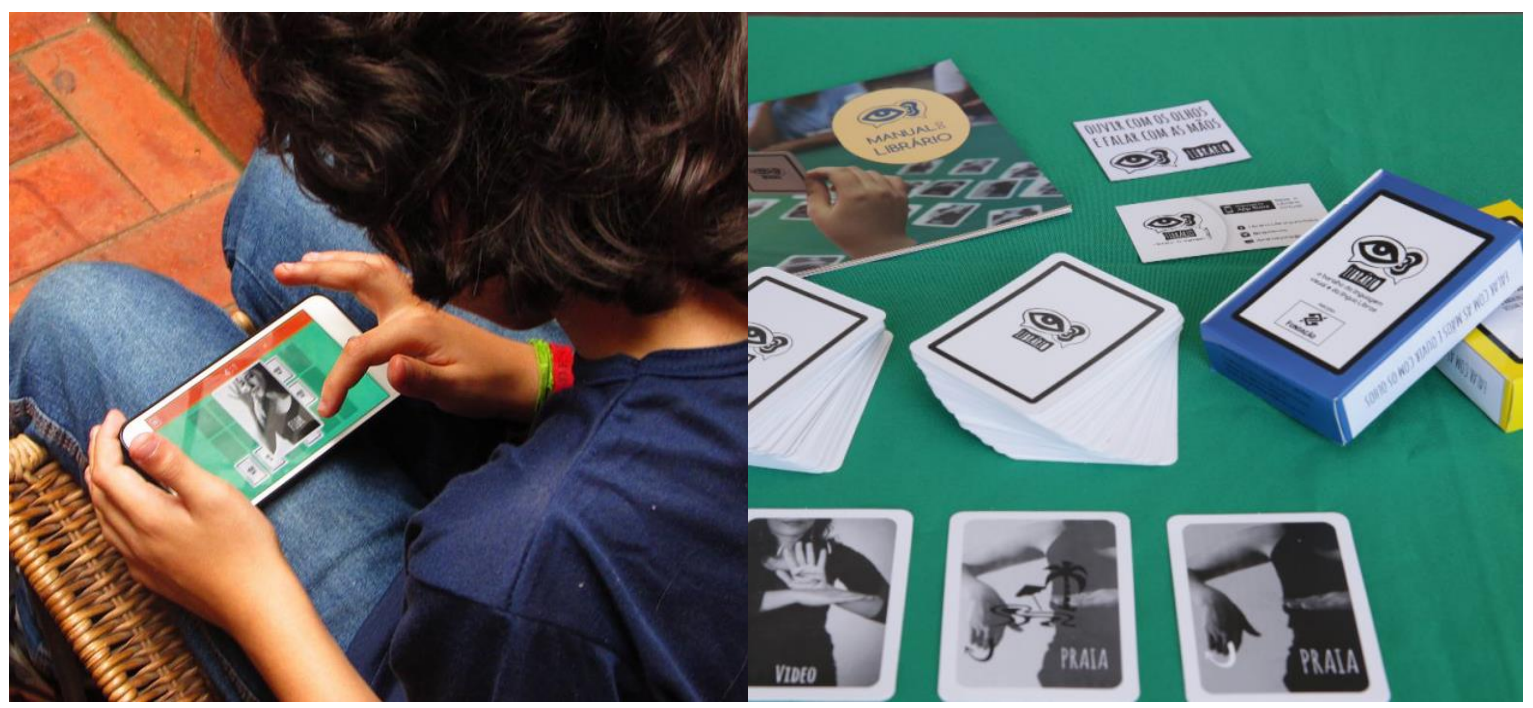

Fonte: Acervo da Pesquisa, 2017 
No entanto, são constantes as solicitações enviadas pelos usuários para que o jogo possa atender aos campos semânticos da Tecnologia, da Matemática, da Biologia, da Gastronomia, do Turismo, entre outros. A língua de sinais em Libras é igualmente extensa quanto o Português. Dessa forma, são necessários estudos para o desenvolvimento de novos baralhos do Jogo Librário que atendam campos semânticos diversos, principalmente às questões ambientais - tema que gera preocupação a todos (ouvintes e surdos).

O Librário conquistou a certificação e o prêmio de Tecnologias Sociais da Fundação Banco do Brasil na categoria Universidades, em 2015, e o Prêmio Brasil Criativo, segunda edição, em 2016, na categoria Games. O desenvolvimento do Librário ocorreu na busca de soluções do projeto de pesquisa $\mathrm{cm}$ objetivo de atender ao ensino básico (CAPES ; FAPEMIG, 2012). O reconhecimento do Librário por instituições respeitadas é justificado pelo potencial inovador e pela simplicidade na execução da proposta.

Desde a sua criação, já foram executadas mais de 200 oficinas de formação de multiplicadores da metolodia do Librário, em instituições de ensino e de cultura do Brasil e que se apropriam da tecnologia social. No Centro Cultural Banco do Brasil de Belo Horizonte (CCBB/BH) foram mais de 1.500 visitantes que participaram de rodadas de jogos semanais em dois anos de multiplicação da proposta, dessa forma, foi multiplicado também nos Centros Culturais Banco do Brasil de São Paulo, Rio de Janeiro e Brasília. O aplicativo do Librário já ultrapassou a marca de 18.000 downloads em todo território nacional e esse número vem crescendo com as oficinas, que ajudam na divulgação da proposta (CASTRO, 2018).

A Libras é a língua brasileira de sinais, fato relativamente novo no contexto no contexto nacional. A sigla Libras foi criada em 1994, pela própria comunidade surda. A aprendizagem da Libras, por muito tempo não foi valorizada pela sociedade. No entanto, em 2002, foi decretada como forma oficial de comunicação dos surdos. Em 2005, foi inserida como disciplina curricular obrigatória nos cursos de formação de professores, e, em 2010 estipuladas às obrigações da presença de seus intérpretes em sala de aula (BRASIL, 2005).

“Imagens são palavras que nos faltaram" (BARROS, 2010, p.26), elas esclarecem muito mais sem a necessidade da língua verbal para entendê-las. A tarefa de ensinar um aluno que não se utiliza da mesma língua dos colegas da classe (na qual está inserido) é um trabalho desafiador.

A insuficiente troca de ideias com outros colegas de sala, a participação em debates, por exemplo, é uma dificuldade para o estudante surdo. Os estudos de design estacam-se por utilizarem a comunicação visual como recurso facilitador para assimilação dos conteúdos, beneficiando diretamente não só o aluno surdo, como também, indiretamente o aluno ouvinte. 
Segundo Delors (2012), na cartilha da UNESCO sobre a educação, utopia necessária perante os múltiplos desafios suscitados pelo futuro, a educação surge como um trunfo indispensável para que a humanidade tenha a possibilidade de progredir na consolidação dos ideais da justiça social.

Considerando as características visuais da Libras e sua estrutura gestual-visual, juntamente as concepções e impactos da tecnologia na sociedade contemporânea e a após a criação do jogo e cartas físico, pensou-se em ampliar o Librário do meio ambiente também para o jogo virtual. De tal forma que permitisse aos usuários acesso, não apenas a imagem bidimensional, mas a todos os parâmetros que compõe a língua - a configuração da mão, o movimento, ponto de articulação, a orientação da mão, a região de contato e as expressões faciais e corporais.

A pesquisa teve como objetivo investigar os conteúdos da temática em Sustentabilidade, Meio Ambiente e Ciências Ambientais e dos sinais em Libras, para o desenvolvimento do Librário Ambiental por meio dos recursos em design e da inclusão social dos surdos.

É importante enfatizar que o Librário com palavras sobre o Meio Ambiente é uma nova versão do Librário. Apresenta-se neste artigo o processo de desenvolvimento do "Librário Ambiental" por meio dos recursos em design e da inclusão social para os surdos. Busca-se facilitar o diálogo entre ouvintes e surdos sobre as questões do meio ambiente, unindo duas vertentes importantes: a inclusão dos surdos e a consciência ambiental.

\section{Desmaterialização - criação do jogo em aplicativo}

A distribuição dos Librários físicos é feita pelo correio (solicitações pelo Facebook) ou pessoalmente nas oficinas. Mas o Librário digital, aplicativo gratuito, mostra que o rompimento das barreiras físicas podem auxiliar muito na distribuição e na questão da acessibilidade. A sociedade vive em uma nova era, rodeada de aparatos tecnológicos. Hoje, a maioria das crianças crescem manuseando tecnologia, habilidade que the confere acesso a um universo ilimitado de saberes e informações.

Nesta perspectiva, Papert (1994) defende o uso de tecnologias na escola como recurso auxiliar na construção de novos conceitos, possibilitando que o processo de aprendizagem ocorra de forma mais prazerosa, uma vez que o enfrentamento de desafios ocorre permeado por um contexto de ludicidade. A possibilidade de conhecer diferentes mundos e ampliar o alcance a partir de uma ferramenta computacional tem sido avaliado por estudiosos como uma metodologia que, se bem conduzida, pode trazer ganhos expressivos para o educando.

Nota-se que existe uma carência de trabalhos que sirvam de guia tanto para educadores quanto para desenvolvedores que pretendem utilizar dispositivos móveis na educação. Dessa forma, esse trabalho desenvolvido com o Jogo Librário tem por objetivo secundário apontar 
novos aspectos pedagógicos que devem nortear construtores de softwares educacionais infantis para dispositivos móveis. Um incentivo para que os professores possam aplicar novas práticas de motivação ao aprendizado da Libras aos alunos. Uma forma de construir a autonomia, instigar a criatividade e curiosidade do aluno de forma interdisciplinar.

Existem questões relevantes, apontadas durante a pesquisa para desenvolvimento do primeiro Librário, com palavras do campo geral: a língua de sinais possui características visuais complexas (sinais, gestos, expressões faciais, etc); há uma limitação de representação em material impresso destes sinais em imagens (tanto para representar objetos tridimensionais, quanto circustâncias do ambiente); limitações financeiras para aquisição de livros tanto nas escolas, quanto às familias de surdos; crescimento dos números de usuários de tecnologias móveis e seus benefícios para a educação já podem ser comprovados em projetos premiados. Dessa forma, por análises dos dados obtidos, adaptou-se o Librário, jogo de cartas para ensino de sinais em Libras associados à palavra em português e imagem iconográfica para uma versão digital. O jogo físico é composto por pares de cartas, semelhante a um jogo de baralho, e pode ser utilizado em qualquer dinâmica que utilize a lógica de pareamento de cartas. Por ser uma Tecnologia Social, o Librário se constitui em uma metodologia simples, acessível e reaplicável por quaisquer recursos, tanto na forma impressa, quanto na adaptação em virtual (CASTRO; MOURÃO, 2018).

\section{Metodologia}

A metodologia para desenvolvimento deste projeto consistirá em pesquisa qualitativa, fundamentada no design, de natureza aplicada. O objetivo do problema foi abordado pelo método descritivo, por dados qualitativos. O método de investigação adotado foi a experimentação. A experimentação, no campo das ciências empíricas, formula hipóteses e as submete a testes, confrontando-as com a experiência, através da observação.

Pode-se definir a experimentação como um conjunto de procedimentos que se estabelecem para verificar as hipóteses. "Ela sempre se realiza em situação de laboratório, ou seja, controlando-se as circunstâncias e variáveis capazes de interferir na relação causa/ efeito estudada. Na experimentação, procura-se verificar se a relação existe mesmo e qual é a proporção de variação encontrada em tal relação" (KAUARK; MANHÃES; MEDEIROS, 2010, p. 67).

A pesquisa se divide nas etapas de: estudos sobre as palavras que possam compor um novo jogo do Librário, elaboração de uma proposta do novo jogo e aplicação experimental da proposta em oficina com a comunidade. Também será aplicado um questionário avaliativo do novo jogo do librário, na etapa de experimentação. Essas etapas estão descritas no relatório final da pesquisa científica, avaliadas pelo coordenador e pelo orientador da pesquisa. 


\section{Desenvolvimento do Jogo Librário Ambiental}

Acredita-se que o jogo Librário, desenvolvido e aplicado no campo semântico geral da Libras, pode ser utilizado para a educação em Sustentabilidade, Meio Ambiente e Ciências Ambientais, através de elaboração de proposta similar, direcionando o campo semântico para o ensino. Dessa forma, a primeira etapa se constituiu na seleção de palavras.

\subsection{Definição das palavras para o jogo}

A seleção das palavras que seriam utilizadas na confecção do Librário do Meio Ambiente ocorreu em duas fases. A primeira se baseou em pesquisa com usuários, online com seguidores das mídias sociais do Librário, através de formulários e da página no Instagram. A segunda fase, pesquisa com o Instituto Mineiro de Gestão das Águas (IGAM), parceiro da pesquisa.

Na primeira fase, os participantes responderam à pergunta "Quais palavras não podem faltar no Librário do Meio Ambiente". Não existiu um número mínimo ou máximo de caracteres, poderiam responder da forma que julgassem mais adequadas.

Num outro momento, foi realizada uma pesquisa através do GoogleForms. Essa pesquisa foi aberta a todo o público da instituição acadêmica. Através do formulário, cada participante deveria responder à pergunta "Quais palavras você quer ver no Librário do Meio Ambiente". Cada participante pode responder livremente e também poderia ser mantido o anonimato.

Os dados coletados pelo Google Forms foram analisados e organizados, juntamente a outras palavras selecionadas pela equipe, a fim de facilitar o estudo posterior dos sinais. As palavras já existentes nas duas categorias do jogo Librário (Geral e da Arte) foram desconsideradas.

A partir dos dados coletados na etapa anterior, as palavras foram devidamente catalogadas, de acordo com suas respectivas fontes. Em um segundo momento, as palavras foram analisadas por intérpretes de Libras, pela equipe de designers e pelo professor surdo da instituição. Em função das dificuldades de transpor uma informação tridimensional (sinal em Libras) para um suporte bidimensional, todas as palavras foram estudadas individualmente. Este cuidado garantiu que o novo Librário se mantivesse nos padrões de qualidades estipulados, atendendo as expectativas da comunidade. Foram realizadas euniões com o professor surdo e suas orientações, em relação aos sinais das palvras, foram registrados em vídeos e fotos.

O professor surdo, que se tornou um aliado importante no projeto, contribuiu para maior credibilidade do produto, perante à comunidade surda. Por ser surdo, o professor carrega consigo toda uma bagagem sobre a cultura do cotidiano dos surdos. Os demais participantes, ouvintes, dificilmente teriam o mesmo nível de entendimento. 
O professor surdo ministra a disciplina de Libras na instituição utilizando os recursos da prática, pois a língua de sinais é visual-espacial. Dessa forma, é essencial o contato direto com o sujeito surdo, nativo a língua, facilitando assim o aprendizado. Os benefícios de ter um professor surdo são significativos, pois ele oferece o contato direto com a cultura surda, sendo um nativo da língua como o desenvolvimento linguístico mais rápido e uso exclusivo de Libras em sala de aula.

\section{Desenvolvimento do protótipo e oficina}

O período de coleta de palavras (que pudessem integrar a nova categoria do jogo Librário Ambiental) ocorreu simultaneamente com a tradução das palavras para a Libras, por questões práticas de análise dos sinais. As palavras foram discutidas individualmente, de forma que o professor surdo pudesse entender melhor o significado das mesmas, e em que contexto estariam inseridas. Muitas palavras, principalmente aquelas de contextos específicos, exigem maior atenção e o sinal possui muitos movimentos, dificultando a adaptação destes para a imagem da carta para o novo jogo.

As palavras que constituem o jogo são: água, amazônia, aquecimento global, bacia, cachoeira, chuva, desmatamento, fauna, flora, lixo, lua, mapa, mar, meio ambiente, natureza, planta, poluição, raiz, reciclagem, respeito, responsabilidade, rio, rocha, semente, sol, terra, vento. Contudo, foi observado que a somatória das palavras do Librário do campo geral, com as palabras do Librário do campo da Arte, contribuem para a formação de frases que contextuam o diálogo da temática em Meio Ambiente.

Após essa etapa de seleção e adapção dass palavras para o jogo, foram realizados registros dos sinais em foto e vídeo para construção do acervo do projeto. Depois de realizada a tradução para a Libras, os vídeos e fotos foram devidamente organizados e posteriormente analisados.

Foram selecionadas as palavras que teriam maior possibilidade de se adequarem ao formato do jogo (carta composta de foto + ícone + seta + palavra em português) visando facilitar o entendimento do usuário. A partir das palavras selecionadas programou-se a realização de sessão de fotos dos sinais, prepando incialmente os sinias que o modelo (pessoa) deveria executar. As fotos foram editadas, conforme estilo característico dos jogos Librário já existentes. Assim, todas as imagens foram transformadas nos padrões e tons preto/branco. Há também um cuidado para o enquadramento da imagem, de forma que os braços, mãos e rosto possam ser visualizados. Além disso, os sinais com movimentos foram representados por "fantasmas" (imagens sobrepostas) dos braços e mãos conforme imagem (Figura 2).

Após o tratamento das imagens foi realizada uma pesquisa de ícones. Buscou-se por ícones que representassem as palavras escolhidas, visando sempre o melhor entendimento dos sinais 
pelos jogadores. Da mesma forma, as setas foram desenhadas indicando o sentido e trajetória do movimento. Posteriormente, as fotos, ícones, setas e palavras em português foram organizadas conforme layout da carta característica do Librário.

Figura 2: Algumas cartas do novo jogo do Librário do Meio Ambiente
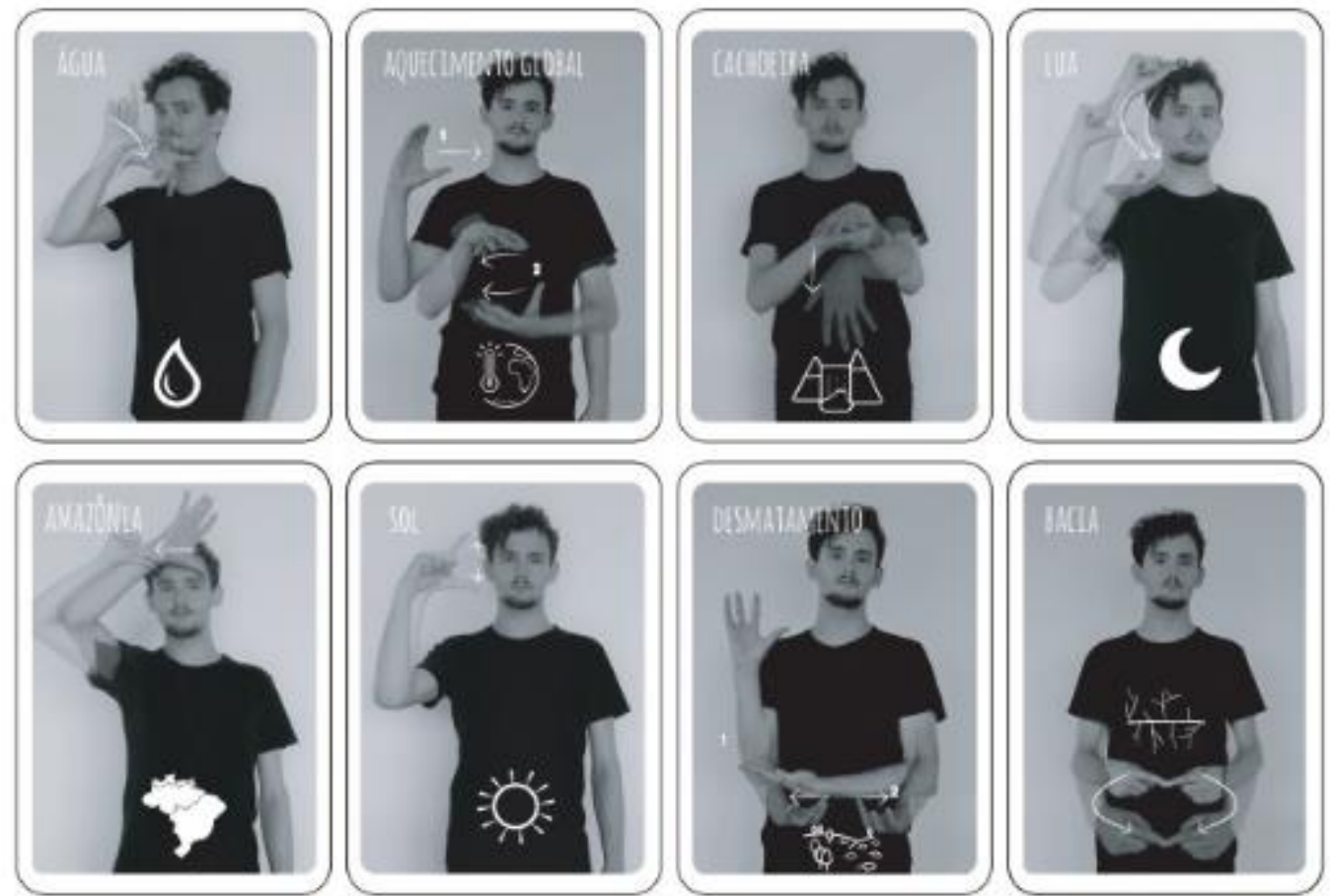

Fonte: Acervo da Pesquisa, 2018.

Para aplicação do protótipo do Librário do Meio Ambiente em oficina (experimental) foi preciso à impressão de dois jogos. A oficina foi realizada na própria instituição de ensino por questões práticas e melhor controle do ambiente. As respostas dos participantes e a experiência prática da oficina serviram de material para análise primária do protótipo (Figura 3).

Figura 3: Oficina do jogo Librário do Meio Ambiente

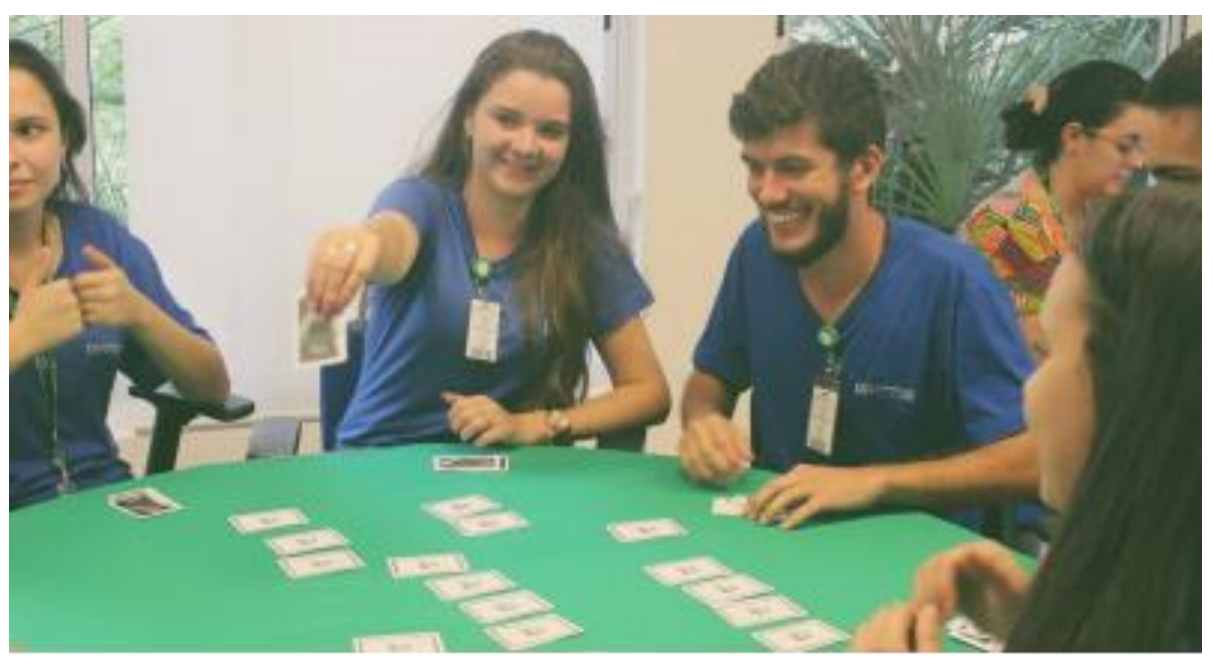

Fonte: Acervo da Pesquisa, 2018. 
Durante a prática do jogo observou-se os participantes conseguiam formular frases em Libras (sinais) com objetivo de entender melhor as questões do Meio Ambiente. Uma das curiosidades dessa etapa foi o interesse dos jovens em dialogar em Libras sobre os efeitos dos impactos ambientas causados pela ação das mineradoras. Uma questão bastante discutida em todos os ambientes do contidiano. Pois, as tragédias causadas por barragens de mineradoras tornaram-se debates de interesse internacioal.

\section{Análise dos resultados}

A realizando a prototipagem de um novo jogo do Librário com palavras no campo semântico da Sustentabilidade, Meio Ambiente e Ciências Ambientais foi um dos objetivos alcançados pela pesquisa. De forma a se adequar melhor aos jogos demais do Librário já existentes, o jogo foi nomeado como "Librário do Meio Ambiente".

Existe na academia a vontade de propiciar a inclusão social. Contudo faltam recursos e materiais pedagógicos para isso. A dinâmica lúdica do jogo tende a ser mais eficaz que os demais processos educacionais, pois trabalha-se com o lado direito do cérebro, aquele responsável pela criatividade e dinamismo (EDWARDS, 2004).

Na figura 4 , apresenta-se a arte de divulgação do Librário do Meio Ambiente, com destaque para o uso da cor verde. A cor verde para a embalagem foi uma proposta indutiva, uma ves que as pessoas podem associar a cor com a simbologia do Meio Ambiente.

Figura 4 : Arte de divulgação do Librário do Meio Ambiente.

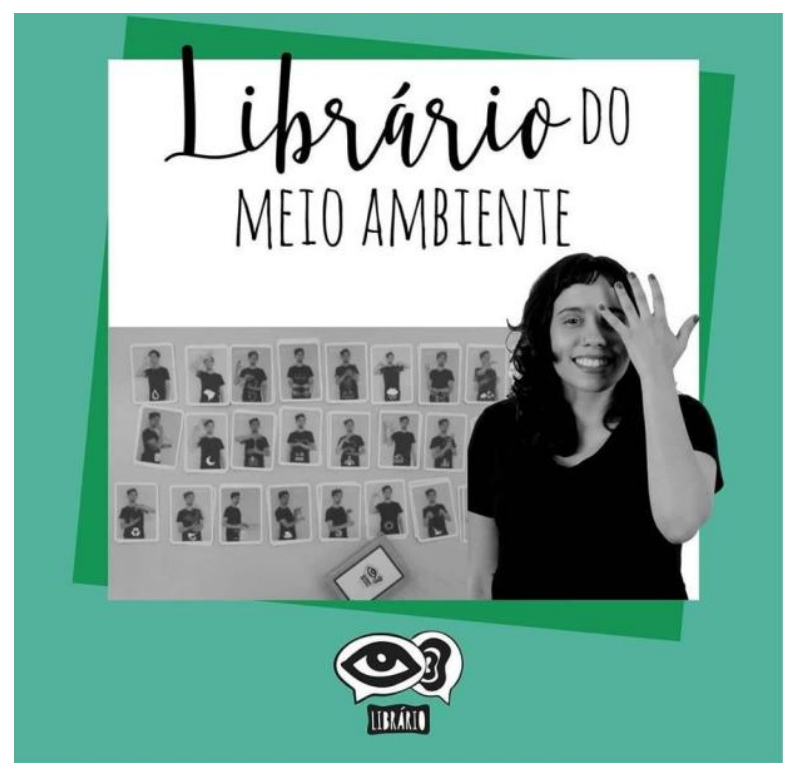

Fonte : Acervo da pesquisa, 2019. 
Por meio da oficina de teste do protótipo do Librário, foi possível coletar alguns dados através de questionário impresso, preenchido pelos participantes da oficina. Foi possível perceber, por meio de conversas informais durante a oficina e das respostas aos questionários, que, independente das dificuldades individuais com a Libras, o Librário é um jogo divertido, que realmente ensina as palavras em libras de forma divertida.

Os ouvintes não possuem nenhuma barreira física, intelectual ou emocional que os impeça de aprender a linguagem de sinais (CASTRO; MARQUES, 2017). Nesse sentido, é muito mais viável que os ouvintes aprendam a Libras do que os surdos tenham que se adequar a cultura ouvinte, através da oralização, por exemplo, que, na história surda, é conhecido como um método controverso. Assim, o Librário atua como uma ferramenta facilitadora da aprendizagem da Libras pelos ouvinte, promovendo a inclusão.

\section{Considerações}

O estudo justificou-se pela necessidade de desenvolver tecnologias sociais que auxiliem na educação e inclusão de surdos e ouvintes, além da demanda do público usuário do jogo por novas categorias de palavras.

Nesse sentido, o Librário do meio ambiente tem capacidade para ser uma importante ferramenta de inclusão, conscientização e educação na perspectiva ambiental. Com uma forte característica democrática, podendo ser usado tanto com surdos quanto ouvintes, em qualquer ambiente, podendo ser replicado facilmente, o jogo é acessível e de grande ajuda no ensino interdisciplinar. É importante ressaltar que o objetivo final do jogo não é ensinar por si só a Educação Ambiental, mas sim auxiliar na inclusão de surdos e ouvintes, principalmente nas escolas, e, especificamente nesse caso, no estudo da Educação Ambiental, Meio Ambiente e Sustentabilidade.

Para estudos futuros, propõem-se novas pesquisas em outras áreas de conhecimentos, de forma a aumentar as categorias de palavras do jogo. Estes estudos poderão ser feitos a partir de novos projetos de pesquisa e extensão, visando ajudar na inclusão dos surdos e na educação e conscientização de todos os indivíduos.

Os projetos sociais que atuam nas mais diversas esferas da sociedade, de organização do terceiro setor e as políticas públicas de governo, associadas às tecnologias sociais, por exemplo, se tornaram um canal ampliado das técnicas, conhecimentos e soluções exitosas. Essas tecnologias podem ser aplicadas em múltiplos contextos, com a participação ativa dos envolvidos e com a replicabilidade em larga escala. 
O desenvolvimento de aplicativos, softwares, produtos digitais, recursos pedagógicos e impressoras 3D, são múltiplas ferramentas do design que na contemporaneidade soluciona problemas e melhora a qualidade de vida. São meios e ambientes capazes de influenciar e viabilizar diferentes inovações. O Design é uma das ciências que mais contribui para o desenvolvimento dos valores intangíveis e inovadores, (Bistagnino, 2009). Por ser em sua essência multidisciplinar e transversal, o design é capaz de ressignificar, repensar e atualizar processos já existentes em diversos campos, possibilitando novos caminhos para um mundo melhor.

\section{Referências}

BARROS, Manoel Wenceslau Leite de. Gramática: O guardador de águas. 2a edição. Rio de Janeiro: Record, 1998.

BISTAGNINO, Luigi. Design sistêmico: uma abordagem interdisciplinar para a inovação. Trad. Lia Krucken. In: Cadernos de estudos avançados em design e sustentabilidade II. MORAES Djion de; KRUCKEN, Lia (Org.). Barbacena, MG: EdUEMG, 2009. p. 13-29.

BRASIL, DECRETO № 5.626, DE 22 DE DEZEMBRO DE 2005. Regulamenta a Lei $\mathbf{n}$ 10.436, de 24 de abril de 2002, que dispõe sobre a Língua Brasileira de Sinais - Libras e o art. 18 da Lei no 10.098, de 19 de dezembro de 2000. Brasília, 22 dez. 2005. Disponível em: <http://www.planalto.gov.br/ccivil_03/_ato2004-2006/2005/decreto/d5626.htm>. Acesso em 10 mai. 2018.

CAPES - Coordenação de Aperfeiçoamento de Pessoal de Nível Superior; FAPEMIG- Fundação de Amparo à Pesquisa do Estado de Minas Gerais. Edital 13/2012 - Pesquisa em Educação Básica Acordo CAPES/FAPEMIG.

CASTRO, F. N. O. Relatório de Atividades do Librário. In: MOURÃO, N. M. Relatório de Atividades do CEDTec - Centro de Estudos em Design e Tecnologia da Escola de Design. Belo Horizonte, UEMG, 2018

CASTRO, F. N. O.; MOURÃO, N. M. Comunicação e a inclusão de surdos: uma proposta do jogo Librário em aplicativo para o ensino. Anais do Simpósio Tecnologias e Educação a Distância no Ensino Superior, Belo Horizonte: UFMG/UEMG, v.1, n.1, 2018. Disponível em: <http://revista.uemg.br/index.php/Simposioteceedadistnoenssuperior/article/view/3036/1724>. Acesso em: 18 jul. 2019.

CASTRO, F. N. O.; MOURÃO, N. M.; ENGLER, R. C. Librário: recursos imagéticos e a educação no contexto dos surdos. Caderno de Educação, ano 19 - n. 48, v.1, p. 71-92, 2016. Disponível em: <http://revista.uemg.br/index.php/cadernodeeducacao/article/view/1854>. Acesso em: 18 jul. 2019.

CASTRO, Fernanda Grazielle Aparecida Soares de; MARQUES, Stela Maria Fernandes. 0 professor de Libras surdo no ensino superior: desafios e perspectivas na atualidade. São Carlos: Pedro e João Editores, 2017. 
DELORS. Jaques. Educação: Um Tesouro a Descobrir. 7.Ed. São Paulo: Editora Cortez, 2012.

Disponível em: <http://unesdoc.unesco.org/images/0010/001095/109590por.pdf>. Acesso em: 07 mai. 2018.

EDWARDS, Betty. Desenhando com o lado direito do celebro. Tradução: Ricardo Silveira. 4으 Edição, 2004.

KAUARK, Fabiana da Silva; MANHÃES, Fernanda Castro; MEDEIROS, Carlos Henrique. Metodologia da Pesquisa: um guia prático. Itabuna: Via Litterarrum Editora, 2010.

PAPERT, Seymour. A máquina das crianças: repensando a escola na era da informática; trad. Sandra Costa. - Porto alegre: Artes Médicas, 1994.

\section{Agradecimentos}

CAPES - Coordenação de Aperfeiçoamento de Pessoal de Nível Superior

FAPEMIG- Fundação de Amparo à Pesquisa do Estadi de Minas Gerais

CEDTec - Centro de Estudos em Design e Tecnologia da Escola de Design/UEMG

Prof. Tuender Durães de Lima (surdo e professor de Libras) 